\title{
Ten years later
}

A decade ago, Regions $\mathcal{E}$ Cohesion started with an editorial article by Harlan Koff and Carmen Maganda, who proposed launching "a multilingual (English, French, and Spanish) and interdisciplinary forum for the discussion of the human and environmental impacts of regional integration as well as governance processes."

In hindsight, we can see that there was a plurality of challenges involved in that project. Let us here single out three of them. The first challenge was analytic, and the critical issue involved was the meaning of "region" and "cohesion." A long-cherished vision referred to region as a level of government that being closer to citizens, is consequently more effective for them. Here, the focus was a different one where the region could be identified with a large area grouping several countries that have been able to develop a thinner integration (transnational regions) or a thicker integration (supranational regions) or be identified with smaller, subnational units again with strong or weak integration. However, whereas the notion of government is more appropriate regarding the smaller units, the notion of governance and the related debate-still from a definitional perspective-is more appropriate for transnational and supranational regions. Cohesion was also a notion carrying a multifaceted meaning with reference to the economic dimensions as well as the social, religious, ethnic, and, more generally, social dimensions. The articles published during this decade directly and indirectly referred to the plurality of meanings we have been mentioning.

The second challenge was openly normative. The starting point was given precisely by connecting the two concepts, region and cohesion, with the entire related debate in terms of ideals and normative goals. Within the normative frame set by Regions $\mathcal{E}$ Cohesion, the principal agent has been the citizen, and every type of region or dimension of cohesion is supposed to respect this tenet, which also is at the base of every democratic arrangement. Moreover, the different form of regionalization and the different ways of affirming and implementing cohesion are goals considered highly worthwhile to be pursued. Finally, cohesion has to be considered a necessary condition of a stable regionalization, and, mutually, regions should actively contribute to cohesion, again in its rich variety of relevant dimensions. 
The third challenge was even more demanding as it meant the promotion of empirical research on all related issues involved in the theoretical and normative challenges. Within the democratic frame just mentioned, Regions $\mathcal{E}$ Cohesion has published 140 academic articles and 52 Leadership Forum contributions during this decade that discussed a variety of topics and presented different positions. Pluralism was a critical aspect that characterized the entire group of published pieces, if taken together.

In 2020, ten years later, are the three challenges still viable and worthy of further pursuit? At least three phenomena that took place in these years are affecting those challenges, and they are worth considering with due care. The first one is the economic crisis that mainly affected all of Europe. Its chief impacts, felt after 2010, went on at least until 2014, but they also affected other areas in other years during that decade. However, the economic crisis that most dramatically affected the entire world is the one that began during the first six months of 2020 as one of the main consequences of the COVID-19 pandemic.

The protracted Great Recession of 2008-2014 and the pandemic in 2020 are profoundly affecting and transforming needs and visions of both regions and forms of cohesion. During the same years, consequently, leaders and people, who were looking for protection and security, are stopping the trend toward globalization. The "America First" slogan used by US President Donald Trump, Brexit, and the democratic deterioration in several countries in different areas of the world compounded by the changes in the multipolar relations by great powers, such as China, the United States, Russia, and by regional powers - for example, Turkey and Egypthas mostly affected the international picture and stopped both regional integration of different sorts and cohesion with an upsurge of inequalities at domestic and international levels.

Third, the neo-populist response by several party leaders not only in most of Europe but also in Latin America and other areas of the world attracted the electoral support of desperate citizens who were ready to embrace all illusions that highly technologically improved propaganda has provided in these last years. In most of the cases, the commitment for cohesion remained on paper, and the integration was openly defied.

In coping with these phenomena, the first analytic challenge can be theoretically enriched. At the same time, the ideals of integration and cohesion have become more needed than before. At the same time, empirical research can find new directions of investigation, as the articles published in this issue are doing regarding the new integrative and more cohesive turn of the European Union, the necessity of a new attention to gender studies and to youth, the new forms of regionalization in a different part of the world in this new situation, and the new needs for ethnic protection. 
Thus, not only are the challenges mentioned previously still with us, but they became even more salient and attention-worthy than ten years ago. Consequently, Regions $\mathcal{E}$ Cohesion still has a promotional task and much work that will be important to publish.

Leonardo Morlino

LEONARDO MORLINO is professor emeritus of political science and President of the International Research Center on Democracies and Democratizations at LUISS, Rome. He was president of the International Political Science Association (IPSA) (2009-2012). He is the author of more than 40 books and more than 200 journal essays and book chapters. He was also one of the three editors of the International Encyclopedia of Political Science (8 vols., Sage Publications, 2011), which won the Honorable Mention of Dartmouth Medal for reference publishing in all domains of knowledge. Morlino is a leading specialist in comparative politics with expertise on Southern and Eastern Europe and a focus on the phenomenon of democratization, and he has just published Equality, Freedom, and Democracy. Europe After the Great Recession, Oxford University Press. 